\title{
May Alcohol-Induced Increase of HDL Be Considered as Atheroprotective?
}

\author{
I. KRÁLOVÁ LESNÁ ${ }^{1}$, P. SUCHÁNEK ${ }^{1}$, P. STÁVEK ${ }^{1}$, R. POLEDNE ${ }^{1}$ \\ ${ }^{1}$ Institute for Clinical and Experimental Medicine, Centre for Cardiovascular Research, Prague, \\ Czech Republic
}

Received February 19, 2009

Accepted June 24, 2009

On-line August 12, 2009

\begin{abstract}
Summary
It is well known that the consumption of moderate doses of alcohol leads to the increase of HDL-cholesterol (HDL-C). Atheroprotectivity of $\mathrm{HDL}$ particles is based primarily on their role in reverse cholesterol transport (RCT). In the study with a crossover design 13 male volunteers were studied in two different regimens: i) drinking of $36 \mathrm{~g}$ alcohol daily and ii) drinking only non-alcoholic beverages, to test whether alcohol-induced increase of HDL cholesterol can affect cholesterol efflux (CHE) from cell culture of labeled human macrophages. Alcohol consumption induced significant $(p<0.05)$ increases of $\mathrm{HDL}$ cholesterol from $1.25 \pm 0.32$ to $1.34 \pm 0.38 \mathrm{mmol} / \mathrm{l}$ and Apo A1 from $1.34 \pm 0.16$ to $1.44 \pm 0.19 \mathrm{~g} / \mathrm{l}$. These changes were combined with a slight increase of cholesterol efflux from $13.8 \pm 2.15$ to $14.9 \pm 1.85 \% \quad(p=0.059)$. There were significant correlations between individual changes of HDL-C and Apo A1 concentrations and individual changes of $\mathrm{CHE}$ ( 0.51 and 0.60 , respectively). In conclusion, moderate alcohol consumption changes the capacity of plasma to induce CHE only at a border line significance.
\end{abstract}

\section{Key words}

Reverse cholesterol transport • Cholesterol efflux • Lipoproteins • Alcohol consumption

\section{Corresponding author}

I. Kralova Lesna, Institute for Clinical and Experimental Medicine

- IKEM, Centre for Cardiovascular Research, Vídeňská 1958/9, 14021 Prague 4 - Krč, Czech Republic. E-mail: ivka@medicon.cz

\section{Introduction}

Several studies have revealed that life style factors including moderate consumption of alcohol positively influence the incidence of cardiovascular disease (Rimm et al. 1999). Both case-control and cohort studies have shown that light and moderate drinkers have higher concentration of HDL particles than non-drinkers (Rimm et al. 1999, Bazzano et al. 2009). HDLcholesterol has been suggested to be the mediator of $40-60 \%$ of the positive effect of alcohol on the incidence of coronary heart disease (Grønbaek 2002).

Reverse cholesterol transport is based on the specific property of a subfractions of HDL particles to induce free cholesterol efflux (CHE) from cells, to bind and esterify free cholesterol and to transport it to the liver for further metabolism or excretion in the stool. This pathway is crucial for protection of peripheral cells from the negative effect of cholesterol.

In the first step of RCT unesterified cholesterol is carried out to the plasma membrane and then is taken up into extracellular space. Although some non-specific processes may be involved (Rothblat and Phillips 1982), the removal of cellular cholesterol is based almost entirely upon the interaction between cellular receptors such as ABCA1, ABCG1 and SR-BI and plasma acceptors. It has been proved (Lin et al. 1999) that a part of intracellular cholesterol leaves macrophages together with endogenously synthesized ApoE. The accepted cholesterol leads to enlargement of the HDL particles. Free cholesterol on the surface of discoidal pre- $\beta$ particles is esterified through LCAT and migrates to the center of particle and promotes further cholesterol efflux. HDL cholesterol is then transported to the liver both directly through interaction of HDL with hepatic SR-BI and indirectly via the transfer of HDL cholesterol esters to triglyceride rich lipoproteins by CETP (cholesterol-ester 
transfer protein) action. These cholesterol esters are brought to the liver in LDL or in chylomicron remnants.

Studies analyzing the effect of alcohol consumption on RCT are rare. Three independent studies identified the positive influence of alcohol intake on CHE from rat hepatoma cells (van der Gaag et al. 2001, Beulens et al. 2004, Sierksma et al. 2004) and one of these studies (Beulens et al. 2004) confirmed the increase of CHE from mouse macrophages.

In this study, a method of cholesterol efflux measurement from human macrophages was used to determine possible changes of alcohol-induced increase of HDL-C. The crucial role of macrophages in the process of atherosclerosis as well as substantial differences in cholesterol cell metabolism between rodents and humans (Oschry and Eisenberg 1982) lead us to choose this cell model.

The complexity of RCT process makes it difficult to evaluate the RCT as a whole from the separate studies of particular steps of RCT. However, to observe such a complexity, the methods that use the diluted serum or plasma as acceptor of cholesterol from cultivated cells may be used. We therefore measured cholesterol efflux in healthy men in whom the HDL cholesterol and apolipoprotein A1 were influenced by the consumption of moderate doses of alcohol.

\section{Methods}

\section{Diets and lifestyle}

The study had a randomized cross-over design. Two 4-week diet modifications were carried out in succession without a washout period. The cross over design of the study was used to minimize all confounding effects. Inclusion criteria were males only, selfmotivation to participate in the study, age between 18 and 50 years, body mass index $<30 \mathrm{~kg} / \mathrm{m}^{2}$ and a normal concentrations of lipoproteins. Exclusion criteria were: use of any medication that could affect study outcomes, consumption of alcohol more than $30 \mathrm{~g}$ daily, diabetes mellitus and/or other major illness as assessed by medical history. None of the subjects used any medication 4 weeks before and during the study. Seven volunteers consumed $36 \mathrm{~g}$ of alcohol (one liter of beer) per day in the first period followed by period of abstinence and the other 6 participants consumed only non-alcoholic beverages in the first part, followed by consumption of one liter of beer per day in succession.

Subjects were asked to continue their normal eating and living habits (except the provided alcohol) with exception of certain decrease of energy intake during period with moderate alcohol consumption to keep constant body weight. Compliance with the protocol was checked by a daily questionnaire. Body weight, waist and hip circumference were measured on the first and last days of the each study period.

The study was approved by the Local Ethic Committee and conducted in accordance with the Helsinki Declaration. All participants provided written informed consent prior to enrolment into the study.

\section{Biochemical data}

Blood samples were obtained by venous puncture at the beginning of the study and at end of each experimental period after a 12-h overnight fast. Samples for lipid analysis were allowed to coagulate at room temperature, serum was separated, portioned, and frozen in duplicate and stored at $-80{ }^{\circ} \mathrm{C}$ until the analysis at the end of the study. Blood samples for cholesterol efflux measurements were taken into tubes containing EDTA as an anticoagulant, placed immediately in ice water and centrifuged at $3700 \mathrm{rpm}$ at $4{ }^{\circ} \mathrm{C}$ for $10 \mathrm{~min}$. The plasma was separated, portioned, and frozen in duplicate and stored at $-80{ }^{\circ} \mathrm{C}$ until the analysis at the end of the study. Plasma triglyceride concentrations, total and low density cholesterol concentrations were determined enzymatically by commercial kits (Roche diagnostics) with autoanalyzer (Cobas Mira Plus). High density lipoprotein cholesterol (HDL-C) concentration was measured after phosphotungstate precipitation of apolipoprotein B (Apo B) containing lipoproteins. The coefficients of variation for lipoprotein assay were less than $3.0 \%$. Non-esterified fatty acid (NEFA) concentrations were measured by enzymatic test (Wako Chemicals GmbH, Neuss, Germany) and Apo A1 and Apo B concentrations by imunoturbidimetric assay (Orion Diagnostica, Espoo, Finland). The coefficients of variation for NEFA and apoliproproteins analyses were less than $7.0 \%$. All biochemical analyses and CHE measurements were performed at the end of the study to eliminate inter-assay variation. All lipoprotein analysis methods in the laboratory were under permanent control by the Center for Disease Control (CDC), Atlanta, GA, USA. LDL cholesterol concentration was also calculated from Friedewald's formula.

\section{Anthropometric data}

Anthropometric data (height, weight, waist 
Table 1. Antropometric parameters.

\begin{tabular}{lcccc}
\hline & Baseline & $\begin{array}{c}\text { Abstinence } \\
\text { period }\end{array}$ & Alcohol period & Statistical significance \\
\hline Weight $(\mathrm{kg})$ & $79.04 \pm 14.15$ & $78.67 \pm 13.91$ & $79.14 \pm 14.12$ & n.s. \\
Body mass index $\left(\mathrm{kg} / \mathrm{m}^{2}\right)$ & $24.75 \pm 4.01$ & $24.64 \pm 3.9$ & $24.79 \pm 3.99$ & n.s. \\
Waist $(\mathrm{cm})$ & $84.00 \pm 8.32$ & $83.86 \pm 8.46$ & $84.04 \pm 8.2$ & n.s. \\
\hline
\end{tabular}

Data are means \pm SD.

Table 2. Biochemical parameters.

\begin{tabular}{|c|c|c|c|c|}
\hline & Baseline & $\begin{array}{l}\text { Abstinence } \\
\text { period }\end{array}$ & Alcohol period & Statistical significance \\
\hline Total cholesterol (mmol/l) & $4.88 \pm 0.74$ & $4.72 \pm 0.40$ & $5.13 \pm 0.88$ & $\mathrm{p}<0.01$ \\
\hline Triglycerides (mmol/l) & $1.19 \pm 0.68$ & $1.24 \pm 0.67$ & $1.24 \pm 0.48$ & n.s. \\
\hline $\begin{array}{l}\text { LDL cholesterol } \\
(\mathrm{mmol} / \mathrm{l})\end{array}$ & $3.27 \pm 0.69$ & $3.23 \pm 0.67$ & $3.50 \pm 0.74$ & $\mathrm{p}<0.01$ \\
\hline $\begin{array}{l}\text { HDL cholesterol } \\
(\mathrm{mmol} / \mathrm{l})\end{array}$ & $1.29 \pm 0.30$ & $1.25 \pm 0.32$ & $1.34 \pm 0.38$ & $\mathrm{p}<0.01$ \\
\hline Apo B $(g / l)$ & $0.94 \pm 0.15$ & $0.93 \pm 0.17$ & $0.98 \pm 0.20$ & n.s. \\
\hline Apo A1 $(g / l)$ & $1.35 \pm 0.17$ & $1.34 \pm 0.16$ & $1.44 \pm 0.19$ & $\mathrm{p}<0.01$ \\
\hline NEFA (mmmol/l) & $0.28 \pm 0.12$ & $0.26 \pm 0.10$ & $0.27 \pm 0.17$ & n.s. \\
\hline Glucose (mmol/l) & $5.5 \pm 0.32$ & $5.68 \pm 0.51$ & $5.57 \pm 0.46$ & n.s. \\
\hline $\mathrm{CHE}(\%)$ & Not measured & $13.80 \pm 2.15$ & $14.90 \pm 1.85$ & $\mathrm{p}=0.059$ \\
\hline
\end{tabular}

Data are means \pm SD.

circumference and body mass index (BMI) were determined at the beginning of the study and at the end of each study period.

\section{Cell culture and efflux measurements}

RCT was measured using human macrophages prelabeled in the medium with $\left[{ }^{14} \mathrm{C}\right]$ cholesterol as described recently in detail (Králová Lesná et al. 2008). Briefly, THP-1 human monocytes (human monocytic leukemia cells, ECACC 88087201) were maintained in RPMI 1640 medium containing $10 \%$ fetal bovine serum, $2 \mathrm{mM}$ glutamine and $1 \%$ penicillin/streptomycin (PAA Laboratoires) at $37^{\circ} \mathrm{C}$ and $5 \% \mathrm{CO}_{2}$.

THP-1 monocytes were seeded into 24-well plates at a density approximately $2 \times 10^{5}$ cells $/ \mathrm{ml}$ in the presence of phorbol 12-myristate 13-acetate (100 ng/ml) (SigmaAldrich) for $72 \mathrm{~h}$ to induce differentiation into macrophages. Before each of the succeeding steps, the cells were washed with phosphate-buffered saline (PBS) (PAA Laboratories), containing $0.1 \%$ fatty acid free bovine serum albumin (FAFA) (PAA Laboratories). THP1 macrophages cells were labeled during a 48-h incubation in a medium containing $\left[{ }^{14} \mathrm{C}\right]$ cholesterol (specific activity $0.2 \mu \mathrm{Ci} / \mathrm{ml}$ ) (PerkinElmer Life Sciences).

These macrophages were subsequently labeled during 48-h incubation in a medium containing $\left[{ }^{14} \mathrm{C}\right]$ cholesterol. To measure cholesterol efflux, cells were incubated for $240 \mathrm{~min}$ in a RPMI medium containing $5 \%$ of plasma of the study subjects (efflux measured between 15 and $240 \mathrm{~min}$ ). Cholesterol efflux (\%) was expressed as the radioactivity of the efflux media divided by total radioactivity of the sample (media plus lysed cells). Each plasma sample was analyzed in triplicate and presented data are means of triplicates. The coefficient of variation for CHE assay was $9.95 \%$.

The measured values of efflux were not corrected to efflux to albumin alone $(6.57 \pm 0.57 \%)$ and they may include the efflux of labeled cholesterol carried with endogenously synthesized ApoE. These parameters should not vary within wells and subjects. 


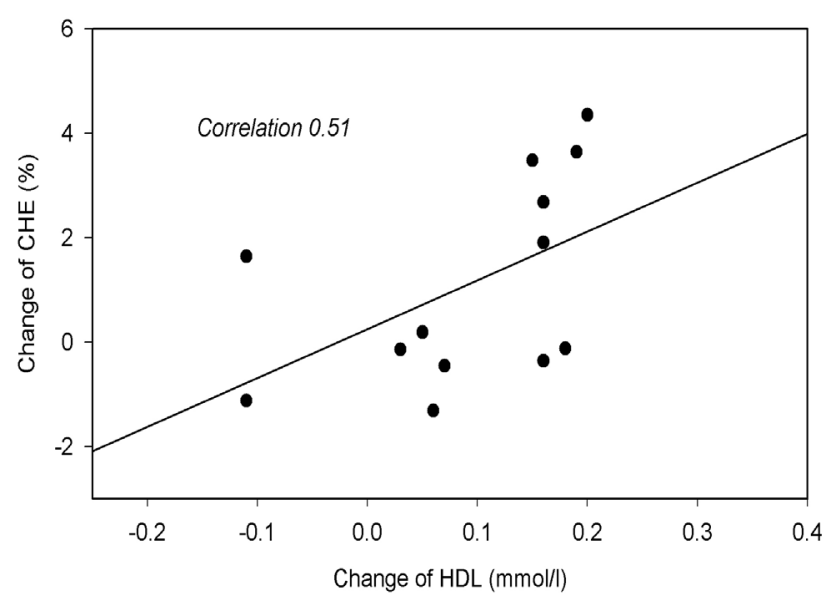

Fig. 1. Relationship between the changes of cholesterol efflux (CHE) induced by 4 weeks of moderate consumption of alcohol and the changes of HDL cholesterol.

\section{Statistical analysis}

All results are expressed as mean $\pm \mathrm{SD}$. The differences between periods were evaluated using a paired t-test. The relationship between changes of $\mathrm{CHE}$ and changes of lipoprotein parameters were analyzed by a simple linear regression.

\section{Results}

The participants of the study were 13 young males (32.31 \pm 5.9 years). No significant changes of body weight and waist circumference were documented during both dietary regimens (Table 1). This may be considered as a good proof of regular weight controls during both experimental periods.

As expected, the alcohol consumption increased HDL concentration by $7.2 \%$ and ApoA1 concentration by $7.5 \%$ (Table 2). Surprisingly, an increase of concentration of total cholesterol and LDL cholesterol ( $8.6 \%$ and $8.3 \%$ respectively) was found. Similarly, a non-significant trend was observed in ApoB and concentrations of triglycerides, NEFA and glycemia were not affected by the alcohol consumption.

CHE was non-significantly higher at the end of drinking period $(14.9 \pm 1.85 \%)$ compared to non-drinking period $(13.8 \pm 1.66 \%)(\mathrm{p}=0.059)$. These results were not affected even after the adjustment for HDL-C and/or Apo A1 concentrations.

On the other hand, positive correlations were found between changes of $\mathrm{CHE}$ and changes of HDL cholesterol and ApoA1 (Figs 1 and 2). The correlation between $\mathrm{CHE}$ change and change of ApoA1 reached a correlation coefficient of 0.60 and the coefficient of

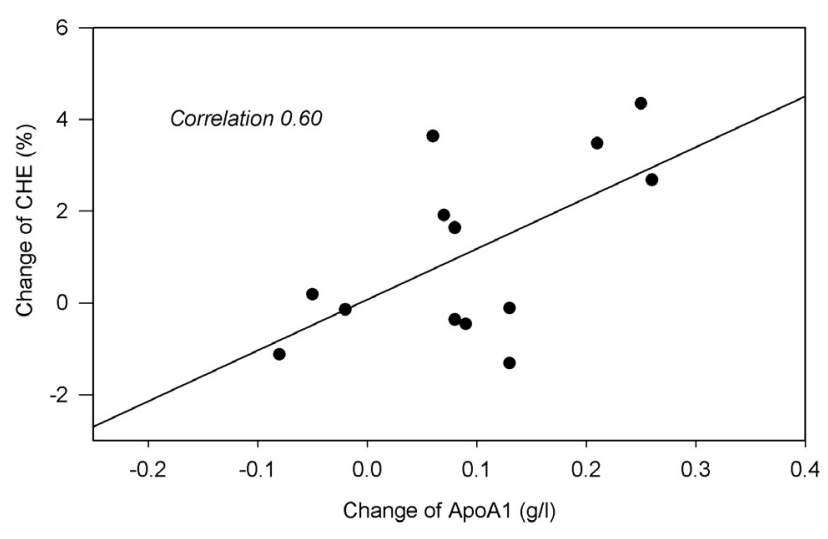

Fig. 2. Relationship between the changes of cholesterol efflux (CHE) induced by 4 weeks of moderate consumption of alcohol and the changes of ApoA1.

correlation to change of HDL concentration was 0.51 .

\section{Discussion}

Controlled alcohol consumption leads to a significant increase of HDL-C and ApoA1 concentrations. Furthermore, individual changes of HDL$\mathrm{C}$ and ApoA1 clearly correlated with individual changes of cholesterol efflux.

The mechanism of alcohol influence on HDL concentration is not clear yet. The study of de Oliveira E Silva et al. (2000), based on investigation of transformed human hepatocytes (Tam 1992, Dashti et al. 1996) suggests that a moderate consumption of alcohol rises HDL-cholesterol primarily by increasing the transport rates of ApoA I and ApoA II. The increase of lipoprotein lipase activity has been repeatedly reported after alcohol consumption (Taskinen et al. 1985, de Oliveira E Silva et al. 2000, Kováŕ and Poledne 2004, Mudráková and Kováŕ 2007), whereas the hepatic lipase activity is lowered (Goldberg et al. 1984, Taskinen et al. 1985) or unchanged (Kováŕ and Poledne 2004) after alcohol intake. Van Tol et al. (1995) found a tendency to an increased esterification rate in the postprandial phase in middle aged men after red wine consumption. Van der Gaag et al. (2001) confirmed this result in a controlled study when he found an increased HDL cholesterol esterification rate by approximately $11 \%$ after 3 weeks of moderate alcohol consumption. On the contrary, Riemens et al. (1997) found no effect on plasma LCAT in persons with a higher consumption of alcohol.

In our study the inclusion of alcohol to diet resulted in a highly significant change of HDL cholesterol but the change of cholesterol efflux was only of borderline significance. 
To the best of our knowledge, our study is the first to demonstrate that an increase of HDL cholesterol elicited by a controlled moderate alcohol consumption correlates with cholesterol efflux from human macrophages. Our results are in agreement with the similar studies (van der Gaag et al. 2001, Beulens et al. 2004) which have described an increase of CHE via ABCA1 receptor to plasma from rat hepatoma cells and mouse macrophages. This increase was confirmed in a group of post-menopausal women (Sierksma et al. 2004). Hoang et al. (2008) found higher CHE to plasma of men with moderate consumption of alcohol compared to abstainers, but a retrospective design with alcohol consumption obtained by questionnaire is a limitation of this study. The results of studies focused on cholesterol efflux in humans with chronic abuse of alcohol lead to less uniform results (Rao et al. 2000, Marmillot et al. 2007).

The measurement of CHE may be affected by the method used. We decided to use modified macrophages because they play a crucial role in the pathogenesis of atherosclerosis. This cell model has been often used in similar studies (Palmer et al. 2004, Mweva et al. 2006, Berrougui et al. 2006), and the involvement of receptors ABCA1, ABCG1 and SR-BI has been proved in these cells (Uehara et al. 2007, Sporstøl et al. 2007). Both the whole diluted sera and the isolated lipoproteins have been used in studies of cholesterol efflux as acceptors of cellular cholesterol. We preferred to use the whole serum because it avoids the pitfall changes of HDL or their subfractions during isolation. Although the use of the whole serum does not allow to discriminate between the relative roles of different pathways and receptors involved in CHE, it is likely that it has the best chance to resemble the situation as it would appear in vivo.

The limitation of our study is in an increase of total and LDL cholesterol after alcohol consumption. Our results are not in agreement with the above mentioned studies. An apparently feasible explanation is the diet composition. The volunteers were asked to maintain their usual diet and their body weight was controlled weekly. As no changes of body weight and other anthropometric parameters were recorded, we might suppose that the energy content of diets (including alcohol energy content) did not substantially differ between both periods. In the
Czech male eating pattern, the alcohol consumption in pubs is usually combined with a consumption of diet high in saturated fats. Thus this difference between the compositions of diets during both periods might be responsible for the increase of total and LDL cholesterol. These increases of the total and LDL cholesterol could be based on the increase of LDL particles, because no change of ApoB concentration was detected.

An extensive meta-analysis of more than forty studies aimed at the influence of alcohol in humans (Rimm et al. 1999) convincingly concluded that the alcohol intake is causally related to a lower risk of coronary heart disease through the changes in lipids and hemostatic factors. The correlation between the individual changes of apolipoprotein A1 concentration and the cholesterol efflux found in our study suggests that the changes in HDL cholesterol as a result of moderate alcohol intake might be related to the changes in reverse cholesterol transport, although results obtained were only of borderline significance.

Several recent studies (de Vries et al. 2005, Berrougui et al. 2007, Králová Lesná et al. 2008) supposed that serum levels of HDL-cholesterol and apolipoprotein A1 may not be an adequate indicator of efficacy of RTC and direct measurement of cholesterol efflux to natural acceptor might represent an improvement of the atherosclerosis risk estimate.

\section{Conflict of Interest}

There is no conflict of interest.

\section{Acknowledgements}

This work was financially supported by Internal Grant Agency of the Ministry of Health of the Czech Republic, Project NR 8486-4.

\section{Abbreviations}

ABCA1 - adenosine triphosphate binding cassette transporter $\mathrm{A} 1$

ABCG1-adenosine triphosphate binding cassette transporter $\mathrm{G} 1$

SR-BI - scavenger receptor B1

LCAT - lecithin:cholesterol acyl transferase

CETP - cholesterol-ester transfer protein

PLTP - phospholipids transfer protein 


\section{References}

BAZZANO LA, GU D, REYNOLDS K, CHEN J, WU X, CHEN CS, DUAN X, CHEN J, HE J: Alcohol consumption and risk of coronary heart disease among Chinese men. Int J Cardiol 135: 78-85, 2009.

BERROUGUI H, CLOUTIER M, ISABELLE M, KHALIL A: Phenolic-extract from argan oil (Argania spinosa L.) inhibits human low-density lipoprotein (LDL) oxidation and enhances cholesterol efflux from human THP-1 macrophages. Atherosclerosis 184: 389-396, 2006.

BERROUGUI H, ISABELLE M, CLOUTIER M, GRENIER G, KHALIL A: Age-related impairment of HDLmediated cholesterol efflux. J Lipid Res 48: 328-336, 2007.

BEULENS JW, SIERKSMA A, VAN TOL A, FOURNIER N, VAN GENT T, PAUL JL, HENDRIKS HF: Moderate alcohol consumption increases cholesterol efflux mediated by ABCA1. J Lipid Res 45: 1716-1723, 2004.

DASHTI N, FRANKLIN FA, ABRAHAMSON DR: Effect of ethanol on the synthesis and secretion of apoA-I- and apoB-containing lipoproteins in HepG2 cells. J Lipid Res 37: 810-824, 1996.

DE OLIVEIRA E SILVA ER, FOSTER D, MCGEE HARPER M, SEIDMAN CE, SMITH JD, BRESLOW JL, BRINTON EA: Alcohol consumption raises HDL cholesterol levels by increasing the transport rate of apolipoproteins A-I and A-II. Circulation 102: 2347-2352, 2000.

DE VRIES R, KERSTENS MN, SLUITER WJ, GROEN AK, VAN TOL A, DULLAART RP: Cellular cholesterol efflux to plasma from moderately hypercholesterolaemic type 1 diabetic patients is enhanced, and is unaffected by simvastatin treatment. Diabetologia 48: 1105-1113, 2005.

GOLDBERG CS, TALL AR, KRUMHOLZ S: Acute inhibition of hepatic lipase and increase in plasma lipoproteins after alcohol intake. $J$ Lipid Res 25: 714-720, 1984.

GRØNBAEK M: Alcohol, type of alcohol, and all-cause and coronary heart disease mortality. Ann N Y Acad Sci 957: 16-20, 2002.

HOANG A, TEFFT C, DUFFY SJ, FORMOSA M, HENSTRIDGE DC, KINGWELL BA, SVIRIDOV D: ABCA1 expression in humans is associated with physical activity and alcohol consumption. Atherosclerosis 197: 197203, 2008.

KOVÁŘ J., POLEDNE R: Influence of moderate alcohol consumption on lipoprotein metabolism (in Czech). Cor Vasa 46: 110-114, 2004.

KRÁLOVÁ LESNÁ I, SUCHÁNEK P, KOVÁŘ J, STÁVEK P, POLEDNE R: Replacement of dietary saturated FAs by PUFAs in diet and reverse cholesterol transport. J Lipid Res 49: 2414-2419, 2008.

LIN CY, DUAN H, MAZZONE T: Apolipoprotein E-dependent cholesterol efflux from macrophages: kinetic study and divergent mechanisms for endogenous versus exogenous apolipoprotein E. J Lipid Res 40: 1618-1627, 1999.

MARMILLOT P, MUNOZ J, PATEL S, GARIGE M, ROSSE RB, LAKSHMAN MR: Long-term ethanol consumption impairs reverse cholesterol transport function of high-density lipoproteins by depleting high-density lipoprotein sphingomyelin both in rats and in humans. Metabolism 56: 947-953, 2007.

MUDRÁKOVÁ E, KOVÁŘ J: Ethanol consumption affects lipoprotein lipase gene expression in C57BL/6 mice. Physiol Res 56: 497-501, 2007.

MWEVA S, PAUL JL, CAMBILLAU M: Comparison of different cellular models measuring in vitro the whole human serum cholesterol efflux capacity. Eur J Clin Invest 36: 552-559, 2006.

OSCHRY Y, EISENBERG S: Rat plasma lipoproteins: re-evaluation of a lipoprotein system in an animal devoid of cholesteryl ester transfer activity. J Lipid Res 23: 1099-1106, 1982.

PALMER AM, MURPHY N, GRAHAM A: Triglyceride-rich lipoproteins inhibit cholesterol efflux to apolipoprotein (apo) A1 from human macrophage foam cells._Atherosclerosis 173: 27-38, 2004.

RAO MN, LIU QH, MARMILLOT P, SEEFF LB, STRADER DB, LAKSHMAN MR: High-density lipoproteins from human alcoholics exhibit impaired reverse cholesterol transport function. Metabolism 49: 1406-1410, 2000.

RIEMENS SC, VAN TOL A, HOOGENBERG K, VAN GENT T, SCHEEK LM, SLUITER WJ, DULLAART RP: Higher high density lipoprotein cholesterol associated with moderate alcohol consumption is not related to altered plasma lecithin:cholesterol acyltransferase and lipid transfer protein activity levels. Clin Chim Acta 258: 105-115, 1997. 
RIMM EB, WILLIAMS P, FOSHER K, CRIQUI M, STAMPFER MJ: Moderate alcohol intake and lower risk of coronary heart disease: meta-analysis of effects on lipids and haemostatic factors. BMJ 319: 1523-1528, 1999.

ROTHBLAT GH, PHILLIPS MC: Mechanism of cholesterol efflux from cells. Effects of acceptor structure and concentration. J Biol Chem 257: 4775-4782, 1982.

SIERKSMA A, VERMUNT SH, LANKHUIZEN IM, VAN DER GAAG MS, SCHEEK LM, GROBBEE DE, VAN TOL A, HENDRIKS HF: Effect of moderate alcohol consumption on parameters of reverse cholesterol transport in postmenopausal women. Alcohol Clin Exp Res 28: 662-666, 2004.

SPORSTØL M, MOUSAVI SA, ESKILD W, ROOSN, BERG T: ABCA1, ABCG1 and SR-BI: hormonal regulation in primary rat hepatocytes and human cell lines. BMC Mol Biol 8: 5, 2007.

TAM SP: Effect of ethanol on lipoprotein secretion in two human hepatoma cell lines, HepG2 and Hep3B. Alcohol Clin Exp Res 16: 1021-1028, 1992.

TASKINEN MR, VÄLIMÄKI M, NIKKILÄ EA, KUUSI T, YLIKAHRI R: Sequence of alcohol-induced initial changes in plasma lipoproteins (VLDL and HDL) and lipolytic enzymes in humans. Metabolism 34: 112-119, 1985.

UEHARA Y, MIURA S, VON ECKARDSTEIN A, ABE S, FUJII A, MATSUO Y, RUST S, LORKOWSKI S, ASSMANN G, YAMADA T, SAKU K: Unsaturated fatty acids suppress the expression of the ATP-binding cassette transporter G1 (ABCG1) and ABCA1 genes via an LXR/RXR responsive element. Atherosclerosis 191: 11-21, 2007.

VAN DER GAAG MS, VAN TOL A, VERMUNT SH, SCHEEK LM, SCHAAFSMA G, HENDRIKS HF: Alcohol consumption stimulates early steps in reverse cholesterol transport. J Lipid Res 42: 2077-2083, 2001.

VAN TOL A, GROENER JE, SCHEEK LM, VAN GENT T, VEENSTRA J, VAN DE POL H, HENDRIKS HF, SCHAAFSMA G: Induction of net mass lipid transfer reactions in plasma by wine consumption with dinner. Eur J Clin Invest 25: 390-395, 1995. 